\title{
Diabetic Ketoacidosis with Cytomegalovirus-Associated Colitis
}

\author{
Kenichi Izumi
}

\begin{abstract}
Cytomegalovirus-associated colitis (CMV colitis) typically occurs in patients in the immunosuppressed state. A diabetic ketoacidosis state further deteriorates immunological functions. However, diabetic patients in a hyperglycemic state developing CMV colitis have been rarely observed. During the course of this study, we came across a case of diabetic ketoacidosis (DKA) with CMV colitis, which is reported herein.
\end{abstract}

Key words: cytomegalovirus-associated colitis, diabetic ketoacidosis

(Inter Med 48: 343-346, 2009)

(DOI: 10.2169/internalmedicine.48.1594)

\section{Introduction}

Cytomegalovirus (CMV) is a commonly occurring virus that causes opportunistic infections (1). Either the immune system of the host eliminates the CMV or the CMV remains latent in the host, and no visible symptoms are manifested in the host. However, in cases where the immune system of the host is weakened or is in an immunosuppressed state, CMV reactivates and begins to rage again. In such cases, the infections may prove to be fatal. Hence, patients infected with CMV and those who have recently undergone some form of immunodeficiency should be given additional care.

Diabetic ketoacidosis (DKA) is a rare complication of diabetes mellitus. Under this condition, there is an accumulation of ketone bodies in the body due to lipolysis, which is caused by insufficient insulin. Since a ketone body is a weak acid, its accumulation in large quantities leads to acidosis. The acidosis state of DKA could cause multiple organ failure and it is a threat to human life. Hence, it can be theorized that DKA impairs immunity $(2,3)$. Many reports agree with this theory, while a few disagree. DKA is often accompanied by diarrhea, and symptoms related to the digestive function often occur unexpectedly. However, it is not certain why diarrhea occurs in patients with DKA. It is our belief that immunity of the gut deteriorates and CMV is reactivated in the colon. In this study, we report the treatment of a DKA patient infected with CMV.

\section{Case Report}

A 78-year-old Japanese woman was hospitalized for unconsciousness and hypotensive shock. Her familial history was recorded, and it was found that her mother and younger sister had type 2 diabetes mellitus. She had developed type 2 diabetes mellitus and hypertension at 35 years of age, and bronchial asthma at 75 years of age. Although she underwent medical examinations, they were not regular. She also suffered from obesity and her blood sugar level had always been high. Her treatment included a diet and exercise regimen and medication with glimepiride $4 \mathrm{mg}$. Her HbAlc level had continued to remain over $8 \%$ for more than a year. Further, she suffered from complications of diabetes mellitus, such as neuropathy, simple retinopathy, and stage 3B nephropathy.

In the winter of 2006, she fell from her bed and broke her ribs. During a period of 10 days after the accident, she did not eat. Instead, she took a high-calorie liquid diet. Later, while her family doctor was on a visit at her home, she lost consciousness and her pulse weakened. Therefore, she was brought to our hospital.

Physical examination on admission: Her height was 138.2 $\mathrm{cm}$; her weight, $52 \mathrm{~kg}$; her BMI, $27.2 \mathrm{~kg} / \mathrm{m}^{2}$; her pulse rate, 70/min with atrial fibrillation; and her blood pressure, 46/20 $\mathrm{mmHg}$. Her consciousness was 30 on the Japan Coma Scale (JCS) and 6/15 on the Glasgow Coma Scale (GCS). Her

Department of Internal Medicine, Matsuyama Red Cross Hospital, Matsuyama 


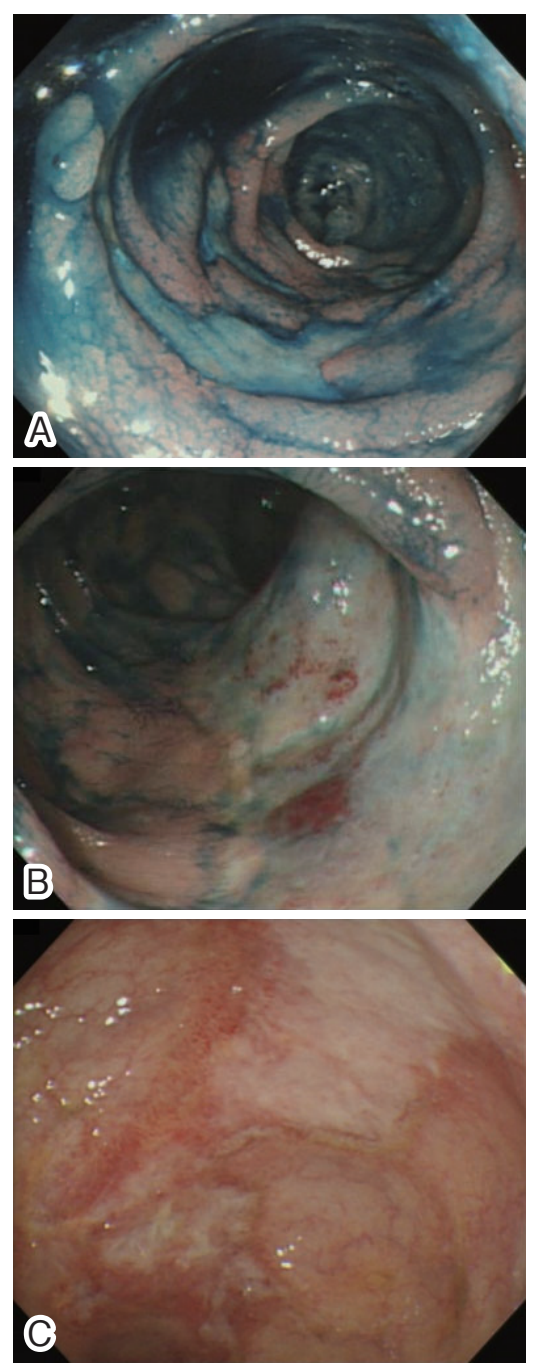

Figure 1. Total colon fiber (TCF) images. A: TCF image: Multiple sigmoid colon ulcerations are observed. B: TCF image: Ulceration in the ascending colon region. C: TCF image: Ulceration in the ileocecal region

rectal temperature was $28.9^{\circ} \mathrm{C}$, and $\mathrm{SaO}_{2}$ was $97.3 \%$ with 4 $\mathrm{L} / \mathrm{min}$ oxygen. Right lower respiratory sound was not audible. Bowel sound was not audible, but large quantities of stool resembling coal tar were excreted.

Laboratory data on admission (Table 1): urine analysis results were positive for occult blood, sugar, and protein. Serum chemistry revealed liver dysfunction, mild rhabdomyolysis, acute renal failure, and mineral disorder. Her plasma glucose was $951 \mathrm{mg} / \mathrm{dL}$ and $\mathrm{C}$ peptide was $4.3 \mathrm{ng} / \mathrm{dL}$. Results of blood gas examinations revealed that the $\mathrm{pH}$ was 7.049; $\mathrm{HCO}_{3}, 9.6 \mathrm{mmol} / \mathrm{L}$; base excess, $-20.1 \mathrm{mEq} / \mathrm{L}$; and anion gap, $32.4 \mathrm{mmol} / \mathrm{L}$. This indicated severe metabolic acidosis. The same serum was later examined; we found that her blood showed diabetic ketoacidosis and lactic acidosis with the quantity of serum ketone bodies totalling 11,710 $\mu \mathrm{mol} / \mathrm{L}$ and serum lactic acid being $60.8 \mathrm{mg} / \mathrm{dL}(=6.7488$ $\mathrm{mM})$.

We found ulcerated parts in the colon (Figs. 1A, 1B, 1C). Tissue staining of the ulcerated parts (Figs. 2A, 2B) of the colon was carried out. An inclusion body was observed in
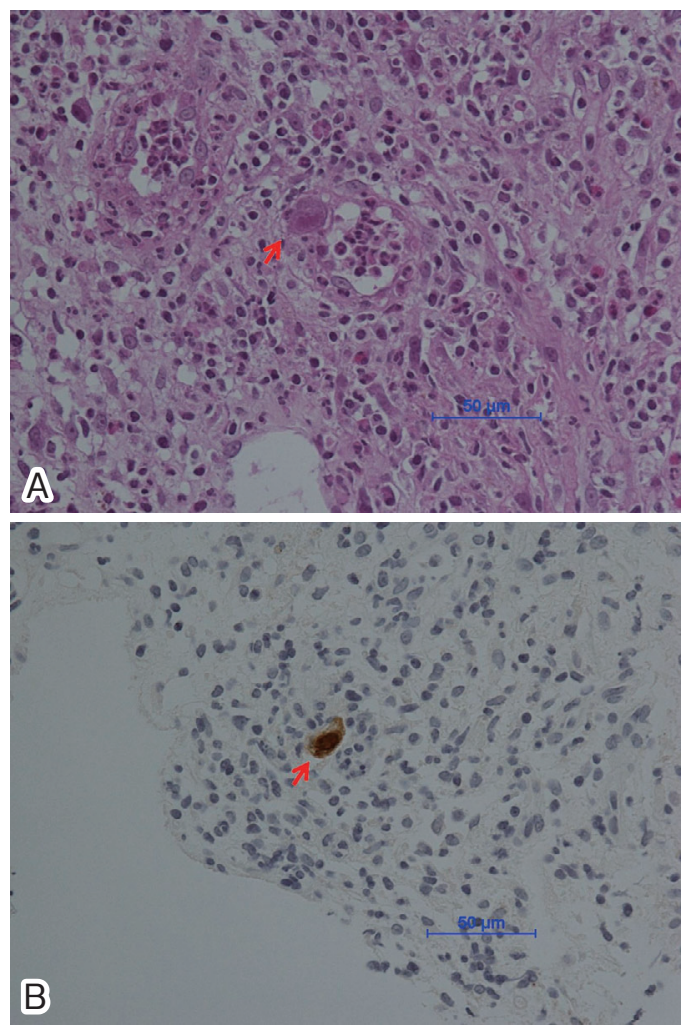

Figure 2. Histological examination of a sample obtained by performing colon biopsy. 2A: Hematoxylin and Eosin staining of the biopsy specimen (arrowhead indicates inclusion body). 2B: Immunostaining for CMV antigen (arrowhead indicates inclusion body).

the mucosa by Hematoxylin-Eosin (HE) staining (Fig. 2A). Immunostaining for $\mathrm{CMV}$ antigen of the same parts is shown in Fig. 2B. The cell with an inclusion body was positively stained. Therefore, we diagnosed her condition as CMV colitis.

Clinical course (Fig. 3): First, we treated the patient with DKA therapy, following which the patient recovered. After the general recovery, she underwent a total colon endoscopic examination, which was delayed because she refused to undergo the examination until the 28th day. CMV colitis was discovered at this time. We treated her with gancyclovir. Symptoms such as abdominal pain and fever were alleviated and stools became normal.

The number of white blood cells returned to the normal range and C-reactive protein (CRP) level was in the process of amelioration. She wanted to leave the hospital, and hence was discharged.

\section{Discussion}

In this case, the patient was treated with many antibiotics. They may have influenced the development of colon lesions. However, on the basis of histopathological findings, colitis was thought to have been caused by CMV.

Few papers have reported cases of diabetes mellitus and CMV colitis. Therefore, it is not yet clear as to whether dia- 


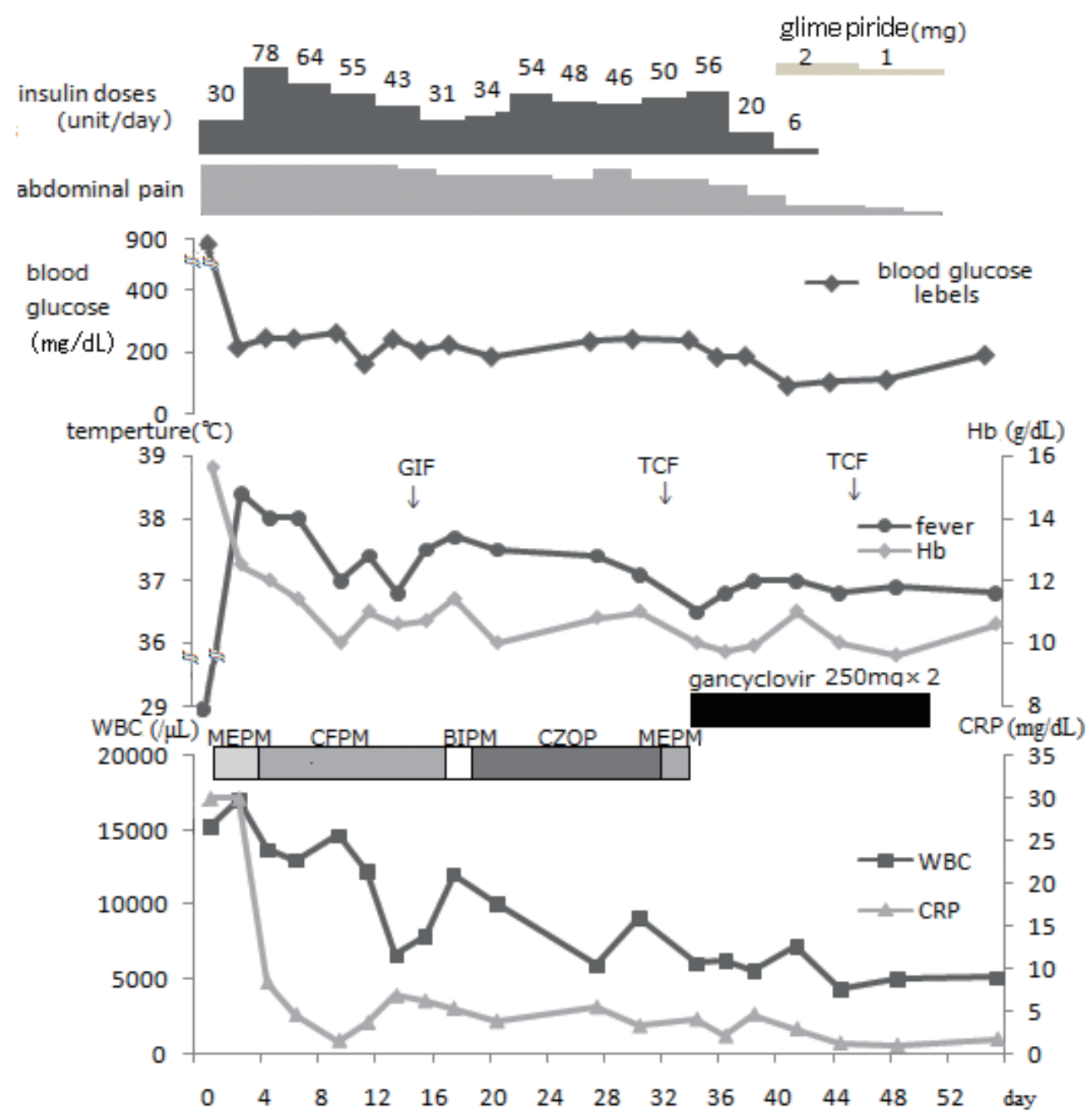

Figure 3. Clinical course.

Table 1. Laboratory Data on Admission

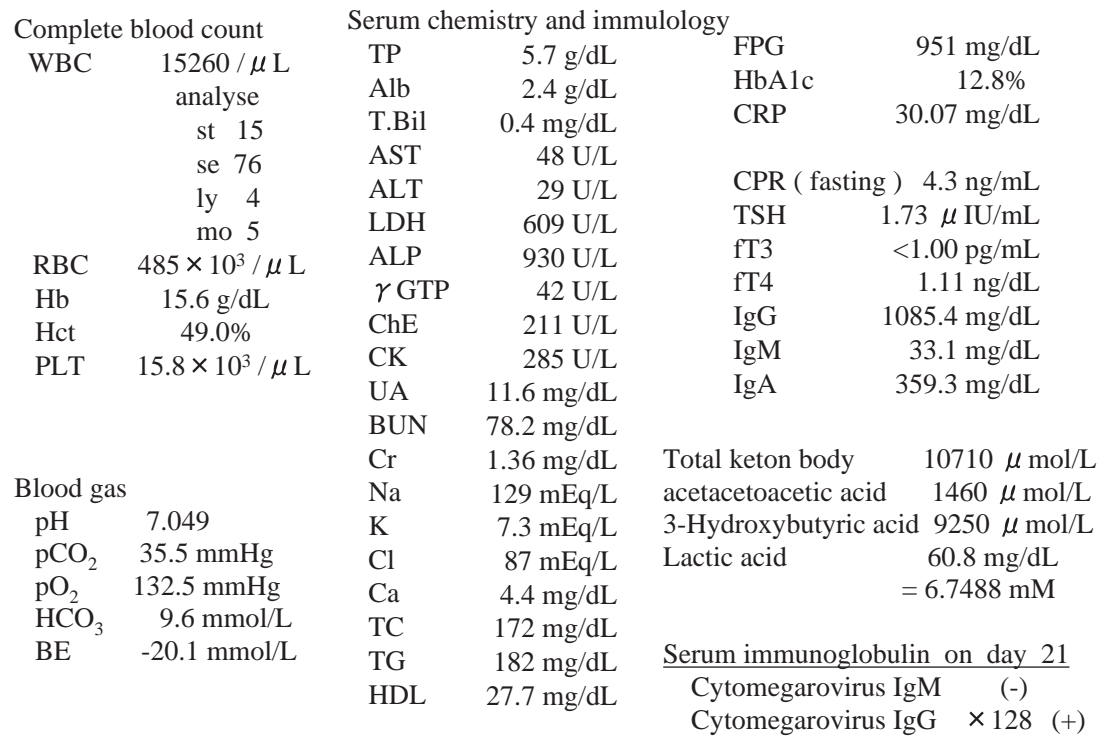

betes is related to CMV colitis or not. However, many reports indicate that poorly-controlled levels of blood sugar in the body may impair immunity. Therefore, we can assume that CMV colitis occurs in patients with poorly-controlled blood sugar levels with altered immunosuppressant states.
We often come across people with high levels of blood glucose, who are easily prone to infection. However, conclusive experimental proof of the impairment of immunity due to high levels of blood glucose does not exist currently. However, it has been reported that a level of over $250 \mathrm{mg} /$ 
$\mathrm{dL}$ of blood glucose causes an impairment of the function of leukocyte phagocytosis in patients (4).

Abnormalities of in vitro lymphocyte response to mitogens in diabetic children during acute ketoacidosis have also been reported (3). Other reports indicate that there may be a defect in the cell-mediated immune function in insulinresistant diabetic and obese subjects (5); further, these reports provide evidence for cell-mediated immunity and specific suppressor T-lymphocyte dysfunction in Grave's disease and diabetes mellitus (6).

With respect to clinical immunity, it has been reported that the patients would benefit from being kept in an ICU for over 5 days, in terms of sepsis and mortality rate, if their blood glucose levels were under $110 \mathrm{mg} / \mathrm{dL}$ (7). However, since these reports were not associated with CMV infections, it was not clear whether high blood glucose was involved in CMV colitis or not. Only those published reports that were related to CMV colitis in diabetic patients without the use of immunosuppressants were admitted (8, 9).

The two diseases, DKA and CMV colitis, may not appear to be correlated. However, would it not be logical to conclude that DKA decreases immunity, which in turn could lead to CMV colitis? The theory seems very plausible, but it is not easy to verify. Therefore, we suggest that patients with DKA and having colitis of unknown origin should be checked for CMV colitis.

\section{Acknowledgement}

We would like to thank Yumi Oshiro, who is a pathologist at Matsuyama Red Cross Hospital, and Takashi Watanabe, who was a gastroenterologist at Matsuyama Red Cross Hospital during this period.

Further, we wish to express our gratitude to all the people associated with this case study.

\section{References}

1. Clyde S, Sanjivini W. Cytomegalovirus. Mandel, Douglas and Bennett's Principles and Practice of Infectious Disease. 4th ed. Churchill Livingstone, New York, 1995: 1786-1801.

2. Wilson RM, Reeves WG. Neutrophil phagocytosis and killing in insulin-dependent diabetes. Clin Exp Immunol 63: 478-484, 1986.

3. Speert DP, Silva J Jr. Abnormalities of in vitro lymphocyte response to mitogens in diabetic children during acute ketoacidosis. Am J Dis Child 132: 1014-1017, 1978.

4. Bagdade JD, Root RK, Bulger RJ. Impaired leukocyte function in patients with poorly controlled diabetes. Diabetes 23: 9-15, 1974.

5. Kolterman OG, Olefsky JM, Kurahara C, Taylor K. A defect in cell-mediated immune function in insulin-resistant diabetic and obese subjects. J Lab Clin Med 96: 535-543, 1980.

6. Topliss D. Evidence for cell-mediated immunity and specific suppressor T lymphocyte dysfunction in Graves' disease and diabetes mellitus. J Clin Endocrinol Metab 57: 700-705, 1983.

7. Van den Berghe G, Wouters PJ, Bouillon R, et al. Outcome benefit of intensive insulin therapy in the critically ill: insulin dose versus glycemic control. Crit Care Med 31: 359-366, 2003.

8. Park YS, Lee DH. CMV colitis in diabetic patient without use of immunosuppressant. Korean J Gastroenterol 45: 151-152, 2005.

9. Yun E, Han J, Choi B. Cytomegalovirus proctitis in a diabetic. Abdom Imaging 24: 39-41, 1999.

(C) 2009 The Japanese Society of Internal Medicine http://www.naika.or.jp/imindex.html 